\title{
Acacia Farnesiana W.
}

Für jeden Norddeutschen ist es sehr auffallend, in Verona zur Winterszeit die zierlichen kleinen lieblich duftenden Bouquets von Acacia Farnesiana in unzähliger Menge Morgens auf dem Markte (Piazza delle arbe) und den ganzen Tag hindurch am Brà den Spaziergängern, und in den Kaffeehäusern von eleganten Blumenmädchen für wenige Kreuzer angeboten zu sehen. Diese Blüthen bilden einen ansehnlichen Handelsartikel, da sie bis nach Genua u. a. 0 . versendet werden. Die Acacia Farnesiana wurde aus ihrem Vaterlande (Haiti, Neugranada, Venezuela etc.) nach Afrika und später nach Europa gebracht, wo sie besonders auf Malta, Sicilien etc. zu einem ansehnlichen Baum heranwächst. Sie gedeiht auch längs der Küste von Genua, an einigen Punkten des Como - und Garda-sees, zur Winterszeit benöthigt sie aber einen Schutz und eine Temperatur von mindestens $25^{\circ} \mathrm{R}$. um sie zu dieser Jahreszeit zur Blüthe zu bringen. Besonders benöthigt di ese Pflanze behufs kräftigen Gedeihens und zahlreicher Blüthe eine trockene bewegte Luft und daher ist ihr bester Standpunkt auf Hügeln in einer gegen Mittag gelegenen Lage. In der Ebene und in Glashäusern, wo die mindeste Feuchtigkeit vorhanden, ist man in Gefahr im Winter keine Blüthen zu erhalten. In Mailand, Mantua, Padua u. a. 0., wenn auch ählich wie Verona gelegen, bringt man die Acacia nicht zu einer so üppigen Blumenflor wie in Verona, wo eine trockene elastische Luft vorherrscht. Die Kultur der Ac. Farnesiana ist sehr einfach. Die Vervielfältigung durch Senker ist sehr unsicher; allen Vorzug verdient die Aussaat. Die Samen keimen mit aller Leichtigkeit in wenigen Monaten, im ersten Jahre erreichen die Pflänzchen schon die Höhe von $21 / 2$ Fuss, manchmal kommen sie schon im dritten Jahre zur Blüthe, gewiss aber immer in vierten Jahre. Es ist absolut nöthig, diese Pflanzen im Freien zu kultiviren; in, wenn auch grossen Töpfen, entfalten sie nie einen schönen Blüthenreichthum. Eine gewöhnliche kieselreiche Erde, reichlich mit Stalldünger und Weintrestern gedüngt, dient der Acacia, die spaliermässig aufgezogen wird. In einer Höhe von $1 / 3-2 / 3$ Fuss vom Boden wird der Hauptstamm abgeschnitten, und $2-3$ secundäre $Z$ weige genügen, um eine grosse Anzahl von Seitenzweigen zu treiben. Zur Sommerszeit müssen alle Penster, ja sogar das Dach des Glashauses beseitigt werden, um der Pflanze in allen Richtungen Luft und Regen zukommen zu lassen. Begossen wird die Pflanze selten.

A. Senoner.

\section{Correspondenz.}

Bei Dur Triest, den 6. Sept. 1860. Bei Durchsicht des speciellen Verzeichnisses der in der
Umgebung von Capodistria einheimischen. Pfanzen in dem letzten Hefte der botanischen Zeitschrift bemerkte ich bei Nr. 163 